\title{
Effects of Eprosartan on Serum Metabolic Parameters in Patients with Essential Hypertension
}

\author{
Evangelos C. Rizos ${ }^{1}$, Athanasia Spyrou ${ }^{1}$, Evangelos N. Liberopoulos ${ }^{1}$, Eleni C. Papavasiliou ${ }^{2}$, Vasi- \\ lis Saougos ${ }^{1}$, Alexandros D. Tselepis ${ }^{2}$, and Moses Elisaf*, ${ }^{*}$
}

\author{
${ }^{I}$ Department of Internal Medicine, Medical School, and ${ }^{2}$ Laboratory of Biochemistry, Department of Chemistry, \\ University of Ioannina, 45110 Ioannina, Greece
}

\begin{abstract}
The effect of the anti-hypertensive drug eprosartan on metabolic parameters is currently not extensively documented. We evaluated the effect of eprosartan on parameters involved in atherogenesis, oxidative stress and clotting activity. This open-label unblinded intervention study included 40 adult patients with essential hypertension taking eprosartan. Eprosartan significantly reduced by $8 \%(\mathrm{p}<0.001)$ the systolic and by $13 \%(\mathrm{p}<0.001)$ the diastolic blood pressure, and increased by $24 \%$ the time needed to produce oxidative by-products ( $\mathrm{p}=0.001$ ), a marker of oxidative stress. In contrast, eprosartan did not alter 8-isoprostane (8-epiPGF2a) levels, another marker of oxidative stress. Additionally, eprosartan reduced by $14 \%$ aspartate aminotransferase and by $21 \%$ then alanine aminotransferase activity, while it had a neutral effect on the lipid profile and apolipoprotein levels and did not influence glucose homeostasis, creatinine and uric acid levels. Eprosartan did not affect the clotting/fibrinolytic status (estimated by plasminogen activator inhibitor 1, tissue plasminogen activator and a2 antiplasmin levels), or the enzymatic activity of the lipoprotein associated phospholipase A2 (LpPLA2) and paraoxonase 1 (PON1). In conclusion, eprosartan should be mainly considered as an anti-hypertensive agent with neutral effects on most of the metabolic parameters in hypertensive patients.
\end{abstract}

Keywords: Eprosartan, hypertension, isoprostane, cholesterol, lipoprotein associated phospholipase A2, glucose.

\section{INTRODUCTION}

Eprosartan is an angiotensin II receptor antagonist approved for the treatment of essential hypertension with particular benefit for the secondary prevention of stroke beyond the absolute level of blood pressure reduction [1,2]. However, the effect of eprosartan on various metabolic parameters is currently not extensively documented. Any such effects may be useful, as vascular damage is considered to be a sequel of various underlying mechanisms that are present in hypertensive patients. Some of these mechanisms involve alterations in clotting/fibrinolytic activity, the oxidative damage of vessels and the inflammatory process [3,4]. Moreover, the lipid profile and glucose homeostasis represent additional well-known risk factors for the development of vascular disease in hypertensive patients [5].

Additional actions that could differentiate some of the anti-hypertensive drugs, even within the same class, may affect the evolution of vascular damage. Therefore, we assessed whether eprosartan exerts additional effects on parameters involved in atherogenesis, oxidative stress and clotting activity, beyond its antihypertensive action.

\section{PATIENTS AND METHODS}

\section{Participants}

This open-label intervention study was conducted in patients attending the Metabolism and Lipid Clinic of the University Hospital in Ioannina, Greece. We included adult

\footnotetext{
*Address correspondence to this author at the Department of Internal Medicine, Medical School, University of Ioannina, 45110 Ioannina, Greece; Tel: +302651097509; Fax: +302651097016; E-mail: egepi@cc.uoi.gr
}

patients with essential hypertension defined as systolic blood pressure $(\mathrm{SBP})>140 \mathrm{mmHg}$ and/or diastolic blood pressure (DBP) $>90 \mathrm{mmHg}$. All individuals were newly diagnosed as hypertensives. Patients with liver or renal disease (serum aminotransferase activity greater than 3-fold (e.g. 120 IU/l), serum creatinine levels $>1.5 \mathrm{mg} / \mathrm{dl}$, hypothyroidism (thyroid stimulating hormone $>5 \mathrm{mIU} / \mathrm{ml}$ ), heavy alcohol consumption ( $>3$ drinks per day) or patients receiving drugs that could affect lipid metabolism, renal or hepatic function, as well as any drug that could affect the parameters examined in the study were excluded. In particular, the diabetic patients who were on oral anti-diabetic medications did not make any change in the drugs or their doses during the study period.

The Ethical Committee approved the study and all participants gave their formal consent. All patients $(n=43)$ were initially advised regarding lifestyle modification and eprosartan $600 \mathrm{mg}$ once daily was administered in those patients who remained hypertensive after a period of 6 weeks $(n=40)$.

\section{Measurements}

All laboratory determinations were carried out after an overnight fast at the beginning of the study and 12 weeks following eprosartan treatment. Serum levels of total cholesterol (TC), high density lipoprotein cholesterol (HDL-C), triglycerides, glucose, transaminases, creatinine and uric acid were determined by standard methods using an Olympus AU600 Clinical Chemistry analyzer (Olympus Diagnostica, Hamburg, Germany). Serum apolipoprotein (Apo) A1, B and E levels were measured using a Behring Nephelometer BN100 and reagents from Dade Behring Holding GmbH (Liederbach, Germany). Serum insulin levels were measured by an AxSYM insulin assay microparticle enzyme immuno- 
assay on an AxSYM analyzer (Abbott Diagnostics). Fibrinogen, a2-antiplasmin, and platelet activator inhibitor-1 (PAI1) were measured by Dade Behring BCS analyzer and tissue plasminogen activator (tPA) by ELISA. Low density lipoprotein cholesterol (LDL-C) was calculated by the Friedewald formula [TC - HDL-C - (TRG /5)], insulin sensitivity with the homeostasis model assessment (HOMA) index ([fasting insulin (mU/L) X fasting glucose $(\mathrm{mg} / \mathrm{dL})] / 405)$, fractional excretion of uric acid with (urinary uric acid X serum creatinine $\mathrm{x} 100$ ) / (serum uric acid X urinary creatinine), and body mass index (BMI) as ( $\mathrm{kg}) /$ height $^{2}(\mathrm{~m})$.

For the estimation of oxidative stress we measured the plasma levels of 8-isoprostane (8-epiPGF2a), as well as the susceptibility to oxidation of total serum lipids. The plasma levels of 8-epiPGF2a were determined by means of a competitive ELISA using a commercially available kit (Cayman Chemicals, Ann Arbor, MI), as we recently described [6]. Oxidation of freshly prepared serum was performed at $37^{\circ} \mathrm{C}$ in the presence of $100 \mu \mathrm{M} \mathrm{CuSO}$. The kinetics of serum oxidation was determined by monitoring the increase in the $245 \mathrm{~nm}$ absorbance, every $10 \mathrm{~min}$ for $6 \mathrm{~h}$. The lag time, which reflects the resistance of serum lipids to copperinduced oxidation, was calculated as previously described $[7,8]$.

Serum paraoxonase 1 (PON1) activity was determined using paraoxon as a substrate in the presence of $2 \mathrm{mM} \mathrm{Ca}^{+2}$ in $100 \mathrm{mM}$ tris-HCL buffer [9]. Lipoprotein-associated phospholipase $\mathrm{A}_{2}$ (Lp-PLA $)_{2}$ activity in total plasma was determined by the trichloroacetic acid precipitation procedure using 1-0-hexadecyl-2-[ ${ }^{3} \mathrm{H}$-acetyl]-sn-glycero-3phosphocholine $\left(\left[{ }^{3} \mathrm{H}\right]-\mathrm{PAF}\right)(100 \mu \mathrm{M}$ final concentration $)$ as a substrate [10]. Lp-PLA ${ }_{2}$ activity was expressed as nmol of platelet activating factor (PAF) degraded per min per $\mathrm{ml}$ of plasma.

\section{Statistical Analysis}

Descriptive statistics for continuous variables expressed as means with standard deviation (SD), or median with mini$\mathrm{mum} /$ maximum range were used. Continuous variables were tested for lack of normality with the Kolmogorov-Smirnov test and, accordingly, comparison of the mean values before and after eprosartan treatment was performed with the paired t-test, while comparison of the median values was assessed with the non-parametric Wilcoxon signed rank test.

Statistical analysis was performed using Statistica version 6.0 (StatSoft Inc, Tulsa, Okla). Significance was defined as $\mathrm{p}<0.05$.

\section{RESULTS}

Forty Caucasians (19 females) with essential hypertension were enrolled in the study. Their mean age was 57 years. Most of them were overweight, 17 had metabolic syndrome according to the updated AHA NHLBI statement (defined as 3 or more of the following: waist circumference $>$ $102 \mathrm{~cm}$ in men and $>88 \mathrm{~cm}$ in women, blood pressure $\geq$ $130 / 85 \mathrm{mmHg}$, triglycerides $>150 \mathrm{mg} / \mathrm{dl}$, HDL-C $<40$ $\mathrm{mg} / \mathrm{dl}$ in men and $<50 \mathrm{mg} / \mathrm{dl}$ in women, and fasting glucose $\geq 100 \mathrm{mg} / \mathrm{dl}$ ), 8 had type 2 diabetes and 18 were smokers (Table 1).
Table 1. Baseline Characteristics of Study Patients

\begin{tabular}{|c|c|}
\hline N (females/males) & $40(19 / 21)$ \\
\hline Age (years) & $57 \pm 11$ \\
\hline Weight $(\mathbf{k g})$ & $77 \pm 15$ \\
\hline BMI $\left(\mathbf{k g} / \mathbf{m}^{2}\right)$ & $28.6 \pm 5.2$ \\
\hline Smokers & 18 \\
\hline Metabolic syndrome & 17 \\
\hline Diabetes & 8 \\
\hline
\end{tabular}

BMI: body mass index.

Mean values \pm standard deviation.

Eprosartan reduced SBP by $8 \%(\mathrm{p}<0.001)$ and DBP by $13 \%(p<0.001)$, while it had a neutral effect on the lipid profile and apolipoprotein levels (Table 2).

Eprosartan did not affect plasma 8-epiPGF2a levels, whereas it significantly increased by $24 \%$ the lag time of total serum oxidation $(145 \pm 54 \mathrm{~min}$ vs $180 \pm 58 \mathrm{~min}$, $\mathrm{p}=0.001$ ) (Table 2). Eprosartan reduced by $14 \%$ the aspartate aminotransferase (form 21 to $18 \mathrm{U} / \mathrm{L}, \mathrm{p}=0.04$ ) and by $21 \%$ the alanine aminotransferase (from 24 to $19 \mathrm{U} / \mathrm{L}, \mathrm{p}=0.05$ ) activity (Table $\mathbf{2}$ ).

The administration of eprosartan had no influence on glucose homeostasis, as well as on creatinine and uric acid levels (Table 2). In addition, eprosartan did not affect clotting or fibrinolytic activity as this was estimated by PAI-1, tPA and a2-antiplasmin (Table 2). The enzymatic activity of Lp-PLA ${ }_{2}$ and PON1 were not altered significantly following eprosartan treatment (Table 2).

\section{DISCUSSION}

We found that eprosartan reduced BP levels, but its effects beyond its anti-hypertensive action were limited. Across a wide range of markers related to atherogenesis, such as lipid metabolism, glucose homeostasis, clotting/fibrinolytic process, oxidative stress, and inflammatory mediators for vascular damage, the only additional finding following eprosartan therapy was the reduction in the susceptibility of serum lipids to oxidation as estimated by the increase in lag time, while 8-epiPGF2a, the other marker of oxidative stress, remained unaltered. Thus, any beneficial effect of eprosartan on morbidity/mortality should be mainly attributed to its anti-hypertensive action.

Atherogenesis is considered to be a complex phenomenon implicating vascular oxidative stress, inflammatory pathways and abnormalities in the coagulation/fibrinolysis equilibrium [11]. We estimated the oxidative stress by measurement of 8-epiPGF2a levels, as well as the lag time for the copper-induced oxidation of lipids. 8-epiPGF2a is the most abundant isomer of the F2-isoprostanes, which are isomers of the F2a prostaglandin produced by nonenzymatic peroxidation of arachidonic acid. 8-epiPGF2a is considered to be a marker of oxidative stress, especially of endogenous lipid peroxidation [12-15]. Interestingly, eprosartan increased by $24 \%$ the time needed to produce oxidative byproducts, while 8 -epiPGF2a levels remained unchanged. The 
Table 2. Serum Metabolic Parameters at Baseline and 12 Weeks Following Eprosartan Treatment

\begin{tabular}{|c|c|c|c|}
\hline SBP (mmHg) & $154 \pm 10$ & $141 \pm 12$ & $<0.001$ \\
\hline TC (mg/dL) & $212 \pm 32$ & $219 \pm 33$ & NS \\
\hline LDL-C (mg/dL) & $134 \pm 24$ & $142 \pm 28$ & NS \\
\hline ApoA1 (mg/dL) & $145 \pm 20$ & $153 \pm 25$ & NS \\
\hline ApoB $(m g / d L)$ & $86 \pm 22$ & $95 \pm 20$ & NS \\
\hline Glucose (mg/dL) & $94 \pm 12$ & $96 \pm 13$ & NS \\
\hline Insulin (mU/L) & $8.8 \pm 3.4$ & $9.9 \pm 5.5$ & NS \\
\hline HOMA index & $2.2 \pm 0.9$ & $2.6 \pm 1.5$ & NS \\
\hline AST (U/L) & $21 \pm 4.6$ & $18 \pm 4.6$ & 0.04 \\
\hline $\operatorname{ALT}(\mathbf{U} / \mathbf{L})$ & $24 \pm 8$ & $19 \pm 8$ & 0.05 \\
\hline Creatinine (mg/dL) & $0.86 \pm 0.11$ & $0.87 \pm 0.12$ & NS \\
\hline Uric acid (mg/dL) & $4.5 \pm 1.5$ & $4.7 \pm 1.4$ & NS \\
\hline FE uric acid (\%) & $13 \pm 6$ & $10 \pm 3$ & NS \\
\hline 8-epiPGF2a (pg/mL) & $61 \pm 20$ & $67 \pm 24$ & NS \\
\hline Lag time (min) & $145 \pm 54$ & $180 \pm 58$ & 0.001 \\
\hline PON1 (U/L) & $60(20-175)$ & $59(27-201)$ & NS \\
\hline Lp-PLA 2 (nmol/mL/min) & $29 \pm 8$ & $34 \pm 16$ & NS \\
\hline
\end{tabular}

SBP: systolic blood pressure; DBP: diastolic blood pressure; TC: total cholesterol; LDL-C: low density lipoprotein cholesterol; HDL-C: high density lipoprotein cholesterol; ApoA1 apolipoprotein A1; ApoB: apolipoprotein B; ApoE: apolipoprotein E; Lp(a): lipoprotein (a); HOMA: homeostasis model assessment index; AST: aspartate aminotransferase; ALT: alanine aminotransferase; FE: fractional excretion; PAI-1: platelet activator inhibitor-1; tPA: tissue plasminogen activator; 8-epiPGF2a: 8-isoprostanes; PON1: paraoxonase 1; LpPLA $_{2}$ : lipoprotein-associated phospholipase $\mathrm{A}_{2}$.

* Mean values \pm standard deviation or median with $\mathrm{min} / \mathrm{max}$ range.

**NS: not significant.

increase of the lag time for LDL oxidation has been previously reported in patients with mild to moderate essential hypertension, and was attributed to the modulation of NADH/NADPH oxidase, which counteracts superoxide production [16].

Eprosartan had no effect on lipid profile, as well as on PON1 and Lp-PLA 2 that are determinants of lipoprotein function and therefore are involved in atherosclerosis. The neutral effect of eprosartan on lipid profile has been previously reported [17], and was also evident in diabetic patients [18]. PON1 and Lp-PLA 2 are enzymes related to the in- flammatory mechanisms that take part in atherogenesis. PON1 is an esterase that is exclusively associated with HDL in plasma and catalyses the hydrolysis of phospholipid hydroperoxides and cholesteryl ester hydroperoxides, which are formed during LDL oxidation. Thus, PON1 may play an important role in the anti-atherogenic activity of HDL. In contrast, Lp-PLA 2 , an enzyme mainly associated with LDL, is currently related to the inflammatory mechanisms of the atherogenic process. Lp-PLA 2 exhibits a $\mathrm{Ca}^{+2}$-independent phospholipase $\mathrm{A}_{2}$ activity and catalyses the hydrolysis of the ester bond at the sn-2 position of the proinflammatory phos- 
pholipid mediator PAF. Lp-PLA 2 also degrades oxidatively fragmented phospholipids, which are formed during the oxidative modification of LDL and are implicated in atherogenesis $[19,20]$. Neither PON1 nor Lp-PLA 2 activity were significantly altered after eprosartan therapy, in accordance with the neutral effect of other anti-hypertensive agents on these enzymes [21].

On the other hand, the decrease of transaminase activity following eprosartan administration was consistent with a similar effect following losartan treatment [22]. These findings should be interpreted with caution, because a liver biopsy was not performed in any of our patients to diagnose non-alcoholic fatty liver disease (NAFLD). However, this reduction in liver transaminases may represent a beneficial effect of angiotensin receptor blockers on NAFLD.

Eprosartan had no influence on glucose homeostasis, as was evident from the measurement of glucose, insulin and HOMA index. Consistent with our results, in experimental studies with animals eprosartan failed to induce peroxisomeproliferator-activated receptor (PPAR) $\gamma$ activity and accordingly failed to demonstrate insulin-sensitizing/antidiabetic effects [23,24]. In humans, eprosartan also has been reported to exert a neutral effect on glucose and insulin levels [17], even in diabetic patients [18].

Eprosartan had a neutral effect on creatinine and uric acid levels, as previously reported [25-27].

Finally, eprosartan did not interfere with the coagulation/fibrinolysis status, although in one report eprosartan seemed to favourably affect these variables [28].

Currently, the anti-hypertensive potency of a drug is considered to be the principal factor that lowers morbidity/mortality and guidelines focus on BP levels as the main target of therapy. In this respect, eprosartan lowered both the SBP and DBP. In contrast, eprosartan had a neutral effect on various metabolic parameters related to the development of vascular disease. The novel findings that eprosartan increased the time needed to produce oxidative by-products and the effect of eprosartan on liver transaminases requires confirmation from larger studies, focusing specifically on eprosartan. This is because there are differences in the properties of the drugs, even in the same class, as was evident from the PPAR $\gamma$ agonist activity of telmisartan and the uricosuric activity of losartan [29].

In conclusion, based on our findings, eprosartan should be mainly considered as an anti-hypertensive medication with neutral effects on most of the underlying metabolic parameters in hypertensive patients.

\section{REFERENCES}

[1] Robins GW, Scott LJ. Eprosartan: a review of its use in the management of hypertension. Drugs 2005; 65: 2355-77.

[2] Schrader J, Luders S, Kulschewski A, et al. Morbidity and mortality after stroke, eprosartan compared with nitrendipine for secondary prevention. Principal results of a prospective randomized controlled study (MOSES). Stroke 2005; 36: 1218-26.

[3] Koh KK, Han SH, Quon MJ. Inflammatory markers and the metabolic syndrome: insights from therapeutic interventions. J Am Coll Cardiol 2005; 46(11): 1978-85.

[4] Paoletti R, Gotto AM Jr, Hajjar DP. Inflammation in atherosclerosis and implications for therapy. Circulation 2004; 109(23 Suppl 1): 11120-6.
[5] Eckel RH, Grundy SM, Zimmet PZ. The metabolic syndrome. Lancet 2005; 365: 1415-28.

[6] Dounousi E, Papavasiliou E, Makedou A, et al. Oxidative stress is progressively enhanced with advancing stages of CKD. Am J Kidney Dis 2006; 48: 752-60.

[7] Mellou F, Lazari D, Skaltsa H, Tselepis AD, Kolisis FN, Stamatis $\mathrm{H}$. Biocatalytic preparation of acylated derivatives of flavonoid glycosides enhances their antioxidant and antimicrobial activity. $\mathrm{J}$ Biotechnol 2005; 116: 295-303.

[8] Schnitzer E, Pinchuk I, Bor A, Fainaru M, Samuni AM, Lichtenberg D. Lipid oxidation in unfractionated serum and plasma. Chem. Phys. Lipids 1998; 92: 151-70.

[9] Tsimihodimos V, Karabina SA, Tambaki AP, et al. Atorvastatin preferentially reduces LDL-associated platelet-activating factor acetylhydrolase activity in dyslipidemias of type IIA and type IIB. Arterioscler Thromb Vasc Biol 2002; 22: 306-11.

[10] Tselepis AD, Dentan C, Karabina SA, Chapman MJ, Ninio E. PAF-degrading acetylhydrolase is preferentially associated with dense LDL and VLDL-1 in human plasma: catalytic characteristics and relation to the monocyte-derived enzyme. Arterioscler Thromb Vasc Biol 1995; 15: 1764-73.

[11] Hansson GK. Inflammation, atherosclerosis, and coronary artery disease. N Engl J Med 2005; 352: 1685-95.

[12] Tsimikas S. Oxidative biomarkers in the diagnosis and prognosis of cardiovascular disease. Am J Cardiol 2006; 98(11A): 9P-17P.

[13] Spirou A, Rizos E, Liberopoulos EN, et al. Effect of barnidipine on blood pressure and serum metabolic parameters in patients with essential hypertension: a pilot study. J Cardiovasc Pharmacol Ther 2006; 11: 256-61.

[14] Morrow JD, Hill KE, Burk RF, Nammour TM, Badr KF, Roberts LJ. A series of PGF2-like compounds are produced in vivo in humans by a noncycloxoxygenase, free radical-catalyzed mechanism. Proc Natl Acad Sci U S A 1990; 87: 9383-7.

[15] Lim PS, ChangYM, Thien LM, et al. 8-Iso-prostaglandin F2alpha as a useful clinical biomarker of oxidative stress in ESRD patients. Blood Purif 2002; 20: 537-42.

[16] Rahman ST, Lauten WB, Khan QA, Navalkar S, Parthasarathy S, Khan BV. Effects of eprosartan versus hydrochlorothiazide on markers of vascular oxidation and inflammation and blood pressure (Renin-Angiotensin system antagonists, oxidation, and inflammation). Am J Cardiol 2002; 89: 686-90.

[17] Levine B. Eprosartan provides safe and effective long-term maintenance of blood pressure control in patients with mild to moderate essential hypertension. Curr Med Res Opin 2001; 17: 8-17.

[18] Derosa G, Ragonesi PD, Mugellini A, Ciccarelli L, Fogari R. Effects of telmisartan compared with eprosartan on blood pressure control, glucose metabolism and lipid profile in hypertensive, type 2 diabetic patients: a randomized, double-blind, placebo-controlled 12-month study. Hypertens Res 2004; 27: 457-64.

[19] Rizos E, Tambaki AP, Gazi I, Tselepis AD, Elisaf M. Lipoproteinassociated PAF-acetylhydrolase activity in subjects with the metabolic syndrome. Prostaglandins Leukot Essent Fatty Acids 2005; 72: 203-9.

[20] Tselepis AD, Chapman JM. Inflammation, bioactive lipids and atherosclerosis: potential roles of a lipoprotein-associated phospholipase A2, platelet activating factor-acetylhydrolase. Atheroscler Suppl 2002; 3: 57-68.

[21] Tambaki AP, Rizos E, Tsimihodimos V, Tselepis AD, Elisaf M. Effects of antihypertensive and hypolipidemic drugs on plasma and high-density lipoprotein-associated platelet activating factoracetylhydrolase activity. J Cardiovasc Pharmacol Ther 2004; 9: 915.

[22] Yokohama S, Yoneda M, Haneda M, et al. Therapeutic efficacy of an angiotensin II receptor antagonist in patients with nonalcoholic steatohepatitis. Hepatology 2004; 40: 1222-5.

[23] Schupp M, Janke J, Clasen R, Unger T, Kintscher U. Angiotensin type 1 receptor blockers Induce peroxisome proliferators activated receptor- $\gamma$ activity. Circulation 2004; 109: 2054-7.

[24] Schupp M, Clemenz M, Gineste R, et al. Molecular characterization of new selective peroxisome proliferators activated receptor $\gamma$ modulators with angiotensin receptor blocking activity. Diabetes 2005; 54: 3442-52.

[25] Puig JG, Torres R, Ruilope LM. AT1 blockers and uric acid metabolism: are there relevant differences? J Hypertens Suppl 2002; 20(5): S29-31. 
[26] Ilson BE, Martin DE, Boike SC, Jorkasky DK. The effects of eprosartan, an angiotensin II AT1 receptor antagonist, on uric acid excretion in patients with mild to moderate essential hypertension. $\mathrm{J}$ Clin Pharmacol 1998; 38(5): 437-41.

[27] Puig JG, Mateos F, Buno A, Ortega R, Rodriguez F, Dal-Re R. Effect of eprosartan and losartan on uric acid metabolism in patients with essential hypertension. J Hypertens 1999; 17(7): 1033-9.

[28] Makris TK, Stavroulakis G, Papadopoulos DP, et al. Eprosartan effect on fibrinolytic/hemostatic variables in arterial hypertension: a comparative study to losartan. Drugs Exp Clin Res 2004; 30: 12532.

[29] Karagiannis A, Mikhailidis DP, Athyros VG, et al. The role of renin-angiotensin system inhibition in the treatment of hypertension in metabolic syndrome: are all the angiotensin receptor blockers equal? Expert Opin Ther Targets 2007; 11(2): 191-205. 